\title{
Brésil: candomblé de Angola. Musique rituelle afro-brésilienne
}

Cérémonie enregistrée au Terreiro Tumbenganga Junçara, Salvador, Bahia, 1999. Maison des Cultures du Monde, 1999

Afro-Brazilian ritual music

François Borel

\section{(2) OpenEdition}

Journals

Édition électronique

URL : http://journals.openedition.org/ethnomusicologie/781

ISSN : 2235-7688

Éditeur

ADEM - Ateliers d'ethnomusicologie

Édition imprimée

Date de publication : 1 janvier 2001

Pagination : 265-266

ISBN : 2-8257-0723-6

ISSN : $1662-372 X$

Référence électronique

François Borel, «Brésil: candomblé de Angola. Musique rituelle afro-brésilienne », Cahiers

d'ethnomusicologie [En ligne], 13 | 2001, mis en ligne le 09 janvier 2012, consulté le 20 avril 2019. URL : http://journals.openedition.org/ethnomusicologie/781

Ce document a été généré automatiquement le 20 avril 2019

Tous droits réservés 


\section{Brésil: candomblé de Angola. Musique rituelle afro-brésilienne}

Cérémonie enregistrée au Terreiro Tumbenganga Junçara, Salvador, Bahia, 1999. Maison des Cultures du Monde, 1999

\section{Afro-Brazilian ritual music}

\section{François Borel}

\section{RÉFÉRENCE}

Brésil: candomblé de Angola. Musique rituelle afro-brésilienne / Afro-Brazilian ritual music. Cérémonie enregistrée au Terreiro Tumbenganga Junçara, Salvador, Bahia, 1999. Enregistrements, notice et photos: Xavier Vatin. 1 CD Inédit/Maison des Cultures du Monde W 260091, 1999.

1 Les musiques de candomblé n'ont jusqu'ici que rarement été éditées en disques, à plus forte raison lorsqu'il s'agissait de présenter celle d'une seule cérémonie rituelle. De plus, les quelques enregistrements publiés ne concernent en général que les candomblé d'obédience yoruba. Pour ce qui est de la «Nation Angola», les documents, s'ils existent, ne sont quasiment jamais disponibles. Ce CD est donc important, d'autant plus qu'il offre le déroulement intégral d'une liturgie dédiée à une divinité du panthéon angola, nommée Gogombira, dieu de la chasse, et qui plus est, enregistrée récemment, en mars 1999.

Comme il le raconte dans l'introduction de la notice du disque, Xavier Vatin a eu le privilège de rencontrer Pierre Fatumbi Verger lors de ses premières investigations dans les milieux des candomblé de Salvador de Bahia. Et c'est lors d'une cérémonie rituelle accompagnée d'une crise de possession qu'il a décidé d'entreprendre ses recherches. (A ce propos, l'auteur de ces lignes se souvient que la participation à un rituel de candomblé l'a incité à s'orienter vers l'ethnomusicologie. Mais c'était en 1969, le contexte sociopolitique n'était pas le même et les candomblé étaient alors considérés comme des foyers 
de subversion. Il m'avait été formellement interdit d'enregistrer le moindre extrait de musique, même à l'aide d'un minable cassettophone Philips!)

La notice est conçue de telle manière que l'auditeur peut suivre exactement le déroulement des différents mouvements. Les passages importants sont même indiqués par des repères en minutes et en secondes, ce qui augmente l'intérêt de l'écoute de l'ensemble du disque qui, au premier abord, est plutôt répétitif. Le texte (en français et en anglais) est clair et bien documenté, faisant appel à des références à Roger Bastide, à Gisèle Cossard-Binon et à Valdina Pinto; quelques photos noir-blanc illustrent en outre certains moments forts de la cérémonie. L'auteur fait l'inventaire des différents cultes présents à Bahia, avant de situer et de caractériser la tradition Angola, qui se distingue en particulier par trois différents rythmes de tambours, cabula, congo et barravento, dont la formule de base nous est fournie grâce à une transcription graphique du jeu de la cloche gã ou agogô qui les accompagne (p. 6). Ici, Vatin aurait pu ajouter que ces rythmes ne sont pas exclusivement d'obédience angola et qu'on les retrouve, sous d'autres appellations, dans les rituels Nago (Ketu, Ijexa), tels qu'ils ont été décrits par certains des auteurs cités en fin de livret, notamment Binon (1967), Oliveira Pinto (1992) et Lühning (1990), ainsi que dans d'autres publications (Béhague 1984, Oliveira Pinto 1986, 1991). Par ailleurs, le rythme congo, "qui suit un schéma de clave caractéristique» (p. 6) se retrouve féquemment associé à des tambourinages en Afrique de l'Ouest, entre autres dans les cultes des vaudouns au Bénin. A propos du chant, il est dit que l'alternance soliste / chœur utilise deux procédés, l'antiphonal et le responsorial. Or la notion de technique antiphonale s'applique en principe à l'alternance de deux chœurs ou demi-chœurs qui se répondent et non, comme le précise l'auteur, à la reprise par le chœur de la même partie que le soliste (p. 6).

4 Cette liturgie débute par le xirê, appel aux divinités angola, chacune ayant son chant attitré entonné par un soliste alternant avec un chœur, le tout accompagné par les trois tambours rum, rumpi et lè (du grand au petit), indissociables de ces rites. Six divinités sont ainsi invoquées (plages 1 à 6), après quoi la cérémonie aboutit à un moment crucial, celui où un ancien initié agite la cloche à battants adjá dont le son induit à lui seul la transe de possession qui se manifeste par un cri (plage 7). Les possédés vont ensuite être revêtus de parures correspondant aux divinités qui les possèdent. Suivent l'entrée des divinités dans le barracão (le local où se déroule le rituel) (plages 8 à 11), l'offrande de nourriture (plages 11-12), et enfin les danses des divinités (plages 13 à 18). La fin de la cérémonie est célébrée par des chants à Lemba, père ancestral de toutes les divinités du panthéon angola. Tous les autres dieux sortent du barracão sous les acclamations de l'assistance, accompagnés une dernière fois par les tambourinaires qui rivalisent de virtuosité et d'enthousiasme. Il est environ une heure du matin, et tous les participants sont conviés à partager le repas préparé par les initiées avant la cérémonie.

L'ensemble des enregistrements restitue parfaitement l'ambiance du moment, et même les arrêts de tambourinage et de chant ont été intégrés aux documents. Le son et le timbre profond des tambours, même s'ils n'ont pas pu être enregistrés de près, permet d'en identifier les différences de tonalités respectives. Les battements de la cloche et ses motifs sont aussi clairement audibles au premier plan. Les chants sont parfois un peu trop discrets et noyés dans l'ensemble. Mais c'est peut-être ce qui confère au disque son caracatère d'authenticité. 